\title{
Acute Equine Grass Sickness in a two-year old Warmblood stallion in Germany
}

\author{
Nina Weltrich', Marion Hewicker-Trautwein ${ }^{2}$ and Rosa Barsnick' \\ 1 Equine clinic Burg Müggenhausen, Weilerswist, Germany \\ 2 Institut of Pathology, Veterinary University Hannover Foundation, Hannover, Germany
}

\begin{abstract}
Summary: Equine grass sickness (EGS) is a frequently fatal disease with a mortality rate of $85 \%$ and more, which can affect all members of the equine family (equidae). The disease results in severe and extensive damage of neurons in both the central and the peripheral nervous system. The gastrointestinal tract is particularly affected although some of the signs of the disease are related to nerve damage in other parts of the body. Much of the characteristic neuronal cell degeneration is found in the nervous system that controls involuntary functions, the autonomic nervous system, hence an alternative name for the disease is 'equine dysautonomia'. In the United Kingdom (UK) this disease is prevalent with the highest incidence worldwide. However, in the rest of Europe it is still a rare disease and there are only very few cases reported in Germany. Many studies tried to discover meteorological and signalement-related risk factors. There are three main forms: acute, subacute and chronic EGS. Each form has different clinical signs. Acute cases present with signs of colic, beginning weight loss and difficulty swallowing. Often large amounts of gastrointestinal reflux and tachycardia are characteristic findings during the initial clinical examination. Horses can also show bilateral ptosis, patchy sweating and muscle fasciculations in all forms. The subacute form is similar to the acute form, only a little bit slower in onset and usually without reflux. In chronic cases massive weight loss and the typical "tucked up" silhovette are predominant. This report presents the case of a two-year old Warmblood stallion in Germany. The horse was referred to the hospital with a suspect neurological disorder. Upon presentation primary neurological signs were not remarkable, but the horse was in bad body condition. It was somnolent, tachycardic and dysphagic, showed signs of colic, and naso-gastric intubation revealed large amounts of nasogastric reflux. Bloodwork revealed marked azotemia. The horse received supportive care including fluids and antiinflammatory drugs. After two days there was no significant clinical improvement and only little fecal output. EGS was suspected and confirmed by a positive phenylephrine-test. Due to lack of clinical improvement, the high certainty of EGS and a bad prognosis, it was decided to euthanize the horse. Postmortem a sample of the ileum was taken for histopathological examination. Upon histopathology, a nearly complete loss of neurons in the ganglia of the enteric autonomic nervous system was apparent. Thus, the case was initially classified as an acute form of equine grass sickness. This case report discusses a horse suffering from EGS and displaying signs of acute, subacute and chronic disease. However, the main purpose of this case report is to raise awareness that grass sickness, although rare, does exist outside of the UK. Additionally, the authors want to draw attention towards the easy to perform phenylephrine-test. Conclusively, Equine grass sickness is a differential diagnosis in horses with colic and gastrointestinal hypomotility, weight loss and dysphagia, even in Germany.
\end{abstract}

Keywords: grass sickness, equine dysautonomia, Germany, autonomic nervous system, phenylephrine, histopathology

Citation: Weltrich N., Hewicker-Trautwein M., Barsnick R. (2018) Acute equine grass sickness in a two-year old Warmblood stallion in Germany. Pferdeheilkunde 432-438; DOI 10.21836/PEM20180504

Correspondence: Nina Weltrich, Heimerzheimer Str. 18,53919 Weilerswist, Germany; weltrich@pferde-klinik.de

\section{Introduction}

Grass sickness is a form of dysautonomic syndrome in the horse which affects mainly postganglionic parasympathetic and sympathetic neurons. There are different forms of dysautonomic syndroms in animals like the Key-Gaskell-Syndrom in cats, or others in dogs, rabbits and hares. The disease is always associated with gastrointestinal hypomotility, dysphagia and Horner syndrome, which is consistently composed of the trias miosis, enophthalmus and ptosis. In horses, ptosis is the most obvious sign.

Grass sickness was first described in eastern Scotland in the early 1900s. The changes in the autonomic nervous system were discovered almost 50 years later (Obel 1955). The UK has the highest incidence of grass sickness in the world, but it has also been reported throughout many Northern European countries. However, published cases from Continental Europe remain rare. In Hungary three outbreaks in the same stud were reported with a suspected carbamate intoxication. This could be a risk factor because it is known that it can cause delayed neurotoxicity in human beings (Schwarz et al. 2012). One case of acute EGS was reported in 1993 from the
Netherlands (Leendertse 1993) and one case of chronic EGS was published in 2004 from Austria (Wlaschitz and Ur). There are also single case-reports from France (Lhomme et al. 1996), Denmark (Bendixen 1946) and Cyprus (Protopapas et al. 2012). Further, six cases of acute EGS were presented at the Clinic for Ruminant and Equine Medicine of the University of Zürich within two years. Some of the horses were from Southern Germany and some were from Switzerland (Wehrli Eser et al. 2000). Besides that, there is only one other report from Germany about chronic EGS in an Icelandic mare on a northfriesian island (Schulze et al. 1997).

As its name suggests, the disease affects mostly grazing horses. During almost 100 years of investigation the causative agent has not been reliably described until today, but several risk factors have been identified. There have been a few studies looking for reasons of meteorological distribution and signalement-related risk factors. The disease seems to affect horses from 2 to 10 years (Wylie et al. 2014). This might result from a different strength of the immune system and its possibility to manage causal agents like Clostridium botulinum type $C$. This organism can produce type $C$ botulinum 
neurotoxin in the gastrointestinal tract of horses and was identified as a potential cause for EGS (Pirie et al. 2014). The specific pathogenesis is still unknown, but Clostridium botulinum type $C$ is mainly suspected as the causative agent of EGS, which in Germany is known as the main causative agent of clinical botulism. Whether the ingestion of clostridia versus the ingestion of preformed toxin results in different clinical signs, is also unknown at this time. Besides that, in the publication from Pirie et al. (2014), a low serum antibody level to Clostridium novyi type $A$ surface antigens is also reported as a risk factor for EGS.

Regarding gender or breed as a predisposition, studies led to different results (Wylie et al. 2014, Wood et al. 1998). Most studies showed no evidence of predisposition in certain breeds, only one study (Wylie et al. 2014) suggested an increased risk for native Scottish breeds. On the contrary, even other types of equids have been reported to suffer from EGS, for example Przewalski s horses (Girling et al. 2017). Apparent metereological risk factors are: more sun hours, periods after cooler weather, dry weather and frost days. The weather changes the metabolism of plants and that could lead to an increase in growth of bacteria like clostridia or fungal organisms. Additionally, changes in plant metabolism can also cause some changes in the horse's gastrointestinal system. For example, increased fructan levels could cause an acidosis of the colon and/or caecum and trigger EGS this way. Cases of EGS are mostly seen between April and July with a peak in May, although they can occur throughout the whole year (Pirie et al. 2014).

There is no clear association with the type of pasture (new ley, permanent pasture, hill grazing, clean or 'horse-sick' pasture) but recent evidence suggests that a high nitrogen content of soil and soil disturbance may be risk factors (Pirie et al. 2014). The excessive occurrence of Ranunculus species (buttercups) on pastures was also investigated as a risk factor (Michl et al. 2011 ). Some factors in pasture management seem important as well. An increased number of horses on the pasture appear to increase the risk of disease (Doxey et al. 1991). Also, changes in management within 14 days prior to the disease are described as risk factors. These include changing fields (Wood et al. 1998), changing feed type or duration and the use of an ivermectin anthelmintic (McCarthy et al. 2004).

There are three main forms of EGS: acute, subacute and chronic. Severity of the disease depends on the extent of neuronal degeneration of the myenteric and submucous plexuses of the enteric nervous system. With acute grass sickness, the symptoms are severe because of an extensive loss of neurons resulting in severe intestinal dysmotility. Clinical symptoms like signs of colic, difficulty in swallowing and drooling of saliva appear suddenly. The horses commonly present with large amounts of gastrointestinal reflux which is caused by small intestinal hypomotility and distention.

Ptosis, pyrexia, patchy sweating and muscle fasciculations can also be present in all forms of EGS (Pirie et al. 2014). The bilateral ptosis results from denervation of sympathetic axons innervating the eye muscles (Hahn and Mayhew 2000). In subacute cases the gastrointestinal reflux is usually absent and the affected horses more often develop a colon impaction. Neuropathy of the ganglion sphenopalatinum inhibits secretion of the nasal mucosa, so often a rhinitis sicca will develop (Pirie et al. 2014). Furthermore, most affected horses show the typical "tucked up" stance. Other clinical signs can be similar to acute cases only less severe and slower in onset. In subacute cases horses usually survive three to seven days. In acute cases the horse will die or require to be euthanized within two days of onset of clinical signs. In chronic cases cachexia is predominant and the characteristic 'tucked up' abdominal silhovette is a constant feature. Furthermore the horses show "weight shifting", similar to horses with laminitis, which is a result of progressive myasthenia (Lyle and Pirie 2009). They often additionally show rhinitis sicca, sweating, muscle tremors and penile prolapse.

Many diagnostic tests were investigated within the last years. However, still the only test with a high specificity and sensitivity (nearly $100 \%$ ) is the histopathological examination of the ileum (Scholes et al. 1993a,b). The ileum is the part of the intestine with the greatest loss of neurons in EGS. The sample can be taken ante mortem by diagnostic laparotomy or celiotomy, both fairly invasive and expensive methods, or the sample is taken post mortem for confirmation of the diagnosis.

When the horse shows an obvious ptosis, like in most cases, a phenylephrin-test can be performed as an ante-mortem clinical diagnostic test. Ptosis in EGS is caused by sympathetic denervation of the smooth muscles in the eyelid. The $\alpha 1$ adrenergic agonist phenylephrine can reverse ptosis in Horner's syndrome of different etiologies, including ptosis in EGS. Eye-drops with $0.5 \%$ phenylephrin should be dropped in one eye. This alpha- 1 adrenergic agonist is similar to the neurotransmitter which is normally responsible for movement of the eye lid muscles. In horses with EGS, a change in the angle of the eyelashes to the head could be easily observed from a frontal view within 30 minutes after administration. A positive result can confirm a suspected EGS as diagnosis (Hahn and Mayhew 2000).

Recently, a study was published that had the aim to find a minimally invasive ante-mortem diagnostic test (Jago et al. $2017)$. In this retrospective case-control study $\beta$-amyloid precursor protein ( $\beta$-APP) immunoreactivity in sections of cranial cervical ganglia, ileum and rectum was compared between EGS horses and a healthy control group. There was an increased immunoreactivity in neuronal perikarya and axons of EGS horses. So, immunolabelled rectal biopsies are of potential diagnostic value for diagnosis of EGS in the future. However, this technique has not yet been established for clinical use and needs further studies.

\section{Case description}

This case report presents a horse with equine grass sickness in Germany. The affected stallion was two years old and was living on a pasture not far away from the stable of his breeders. He was transferred to this pasture together with his herd six days before onset of the disease. None of the other cograzing horses of similar age were affected. The farm is near the equine hospital, and the equine population of the farm is well known by one of the clinic veterinarians. Therefore, it is certain that there has not been any similar case on this farm in the last 20 years. It was in mid-June of 2017 when the hor- 
se suddenly appeared ill. The weather was unsettled at this time with some rainy and some sunny days.

The two-year old stallion was examined by the referring veterinarian because of seemingly neurologic signs and was then referred to the hospital. On examination the horse was very somnolent and dull. Considerable weight loss and bilateral ptosis were remarkable. Heart rate was 60 beats/min, respiration rate was 20 breaths/min, and temperature was $37.5^{\circ} \mathrm{C}$. Mucous membranes were normal but capillary refill time was prolonged to three seconds. Abdominal auscultation revealed decreased gut sounds. On rectal examination a full urinary bladder and taut large intestinal bands were found. The horse seemed to be painful upon palpation. Nasogastric intubation revealed almost 20 liters of spontaneous nasogastric reflux. Abdominal ultrasonography showed a lot of dilated small intestine and primarily a distended duodenum. The stomach was still fluid-filled.

Hematology revealed leukocytosis (15.23 $\left.\times 10^{9} / \mathrm{L}\right)$, neutrophilia and monocytosis (Table 1), hematocrit was within normal limits. Serum biochemistry abnormalities were limited to severely increased creatinine and urea (azotemia), hypocalcemia and slightly increased AST and GGT (Table 1). lonized calcium was also low (1.34 mmol/L). Electrolytes (potassium, chloride, sodium) were within normal limits. Total protein was $65 \mathrm{~g} / \mathrm{L}$.

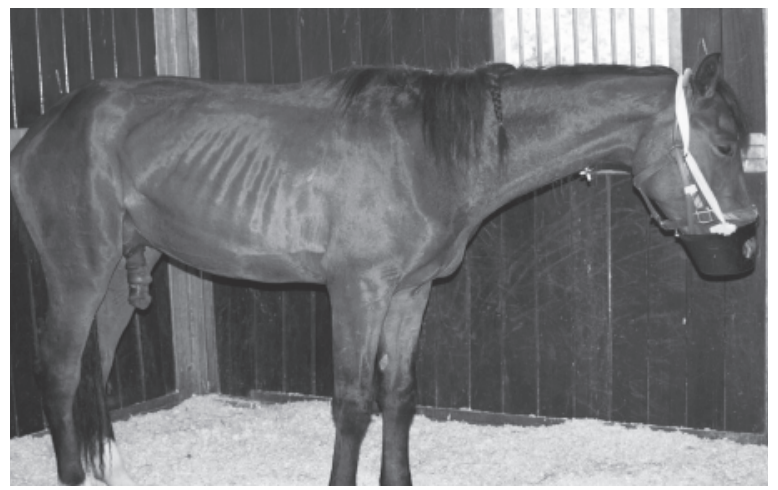

Fig. 1 Cachexia, typical posture and obtundation in a horse with acute grass sickness.

Kachexie, typische Körperhaltung und Apathie bei einem Pferd mit akuter Graskrankheit

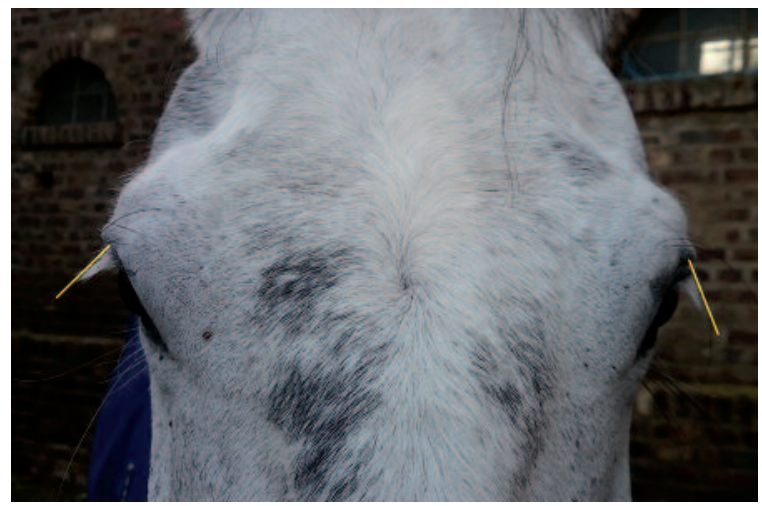

Fig. 2 Horse with EGS after administration of $0.5 \%$ - phenylephrin eyedrops in the right eye (note ptosis in left eye vs. changed angle of the eyelashes in right eye).

Pferd mit Graskrankheit nach Eingabe von 0,5\% -Phenylephrin-Augentropfen in das rechte Auge (zu beachten ist die Ptosis am linken Auge im Vergleich zum veränderten Winkel der Wimpern im rechten Auge)
Volume replacement included lactated Ringer's supplemented with calcium-boro-gluconate (infusion rate $90 \mathrm{ml} / \mathrm{kg} /$ day). The indwelling nasogastric tube was checked every three hours and about two to four liters of reflux were obtained every time. A urinary catheter was placed multiple times a day. Urine looked normal and specific gravity as well as dipstick analysis (Combur-Stick) were normal. The horse remained lethargic and always stood a little bit "tucked up". Penile prolapse became obvious as well (Fig. 1). Dysphagia could be observed, but sometimes the horse seemed to be thirsty, however, he was not offered any water due to gastrointestinal reflux.

Treatment included flunixin-meglumine (1.1 mg/kg, IV, q12 h) starting on day 2, after azotemia had resolved significantly. The day after initial examination the horse was still tachycardic with 60 beats/min and gastrointestinal sounds were still decreased. Temperature dropped to a subnormal range of approximately $36.7^{\circ} \mathrm{C}$. Ultrasound examination revealed similar findings as the day before with some moderately dilated small intestine with reduced motility and moderately thickened walls. The horse showed little fecal output and rectal examination revealed a rather empty large intestine. Oral mucous membranes were pink and moist, and capillary refill

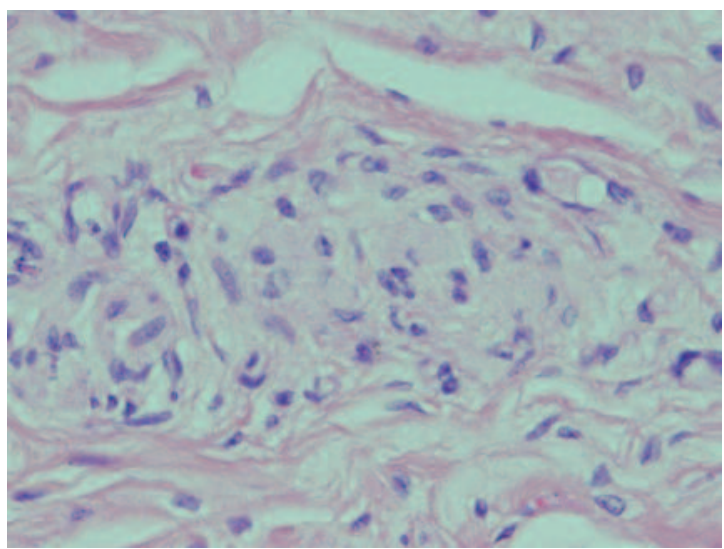

Fig. 3a Submucosal ganglion in the ileum of a horse affected by grass sickness with completely missing nerve cells and numerous nuclei of preserved satellite cells. $\mathrm{HE}, \times 400$

Submukosales Ganglion im Ileum bei einem Pferd mit Graskrankheit mit vollständigem Fehlen von Nervenzellen und zahlreichen Kernen erhalten gebliebener Satellitenzellen. HE, $\times 400$

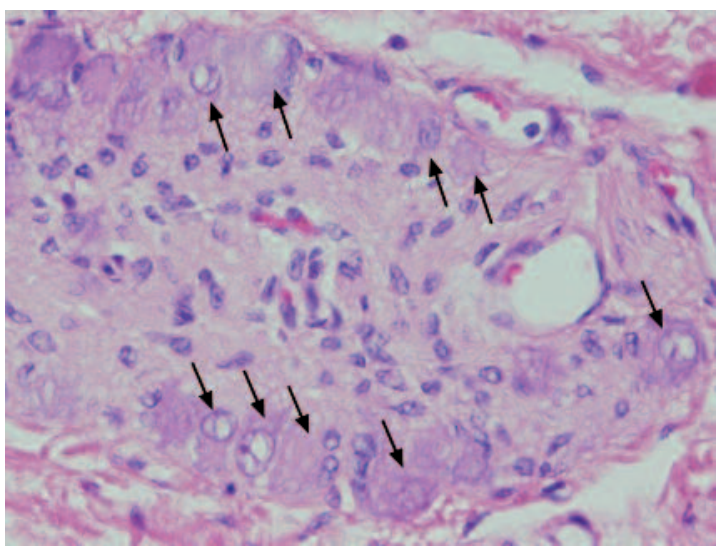

Fig. $3 b$ Submucosal ganglion in the ileum of a control horse with several normal nerve cells and nuclei of normal satellite cells. HE, $\times 400$

Submukosales Ganglion im Ileum eines Kontrollpferdes mit mehreren normalen Nervenzellen und Kernen normaler Satellitenzellen. HE, $\times 400$ 
time was two seconds. The nasal mucous membranes had become inflamed and dry, likely due to the lack of physiological secretions. Hematology showed a decreased hematocrit of $27 \%$ after 12 hours of fluid therapy. Total white blood cell count was $11.45 \times 10^{9} / \mathrm{L}$ still with neutrophilia and monocytosis. Creatinine had decreased significantly and was within normal limits $(100 \mu \mathrm{mol} / \mathrm{L})$, but urea remained markedly increased $(35.8 \mathrm{mmol} / \mathrm{L})$. Total serum calcium and ionized calcium had both increased but were still slightly below normal. AST was slightly increased and GGT was within normal limits. Total protein had decreased to $53 \mathrm{~g} / \mathrm{L}$.

On day three, still no signs of clinical improvement could be noted. The horse had progressively lost weight during hospitalization. A phenylephrine test was performed. Eye drops with $0.5 \%$ phenylephrine were applied on the cornea of the right

Table 1 Laboratory findings (comparison first and second day) / Laborbefunde (Vergleich zwischen erstem und zweitem Tag)

\begin{tabular}{|c|c|c|c|}
\hline Parameter Haematology & Normal value range & Day 1 & Day 2 \\
\hline $\operatorname{RBC}\left(\times 10^{\wedge} 12 / L\right)$ & $6.4-10.4$ & 9.44 & 7.63 \\
\hline $\mathrm{HCT}(\%)$ & $30-47$ & 34 & 26.7 \\
\hline HGB $(g / d L)$ & $10.7-16.5$ & 13.5 & 10.9 \\
\hline WBC (x 10^9/L) & $4.9-11.1$ & 15.23 & 11.45 \\
\hline $\operatorname{NEU}\left(\times 10^{\wedge} 9 / L\right)$ & $2.5-6.9$ & 11.51 & 8.09 \\
\hline $\operatorname{LYM}\left(\times 10^{\wedge} 9 / \mathrm{L}\right)$ & $1.5-5.1$ & 2.71 & 2.72 \\
\hline MONO (x 10^9/L) & $0.2-0.6$ & 0.96 & 0.63 \\
\hline $\operatorname{EOS}\left(\times 10^{\wedge} 9 / \mathrm{L}\right)$ & $0-0.8$ & 0 & 0 \\
\hline BASO (x 10^9/L) & $0-0.1$ & 0.05 & 0.01 \\
\hline $\mathrm{PLT}(\mathrm{K} / \mu \mathrm{L})$ & $100-250$ & 287 & 250 \\
\hline \multicolumn{4}{|l|}{ Parameter serum biochemistry } \\
\hline GLU (mmol/L) & $3.56-8.34$ & 7.93 & 5.21 \\
\hline UREA (mmol/L) & $3.6-8.9$ & $>46.4$ & 35.8 \\
\hline CREA $(\mu \mathrm{mol} / \mathrm{L})$ & $71-194$ & Values higher than 1202 & 100 \\
\hline $\mathrm{CA}(\mathrm{mmol} / \mathrm{L})$ & $2.6-3.22$ & 2.04 & 2.36 \\
\hline $\mathrm{TP}(\mathrm{g} / \mathrm{L})$ & $56-79$ & 65 & 53 \\
\hline ALB $(g / L)$ & $19-32$ & 32 & 24 \\
\hline GLOB $(g / L)$ & $24-47$ & 33 & 29 \\
\hline AST (U/L) & $100-600$ & 857 & 657 \\
\hline $\operatorname{ALKP}(\mathrm{U} / \mathrm{L})$ & $10-326$ & 262 & 226 \\
\hline GGT (U/L) & $0-87$ & 105 & 84 \\
\hline TBIL $(\mu \mathrm{mol} / \mathrm{L})$ & $0-60$ & 49 & 35 \\
\hline CK (U/L) & $10-350$ & 271 & 280 \\
\hline $\mathrm{LDH}(\mathrm{U} / \mathrm{L})$ & $250-2070$ & 1662 & 1380 \\
\hline
\end{tabular}

Parameter venous blood gas

$$
\mathrm{pH}
$$

$\mathrm{HCO} 3(\mathrm{mmol} / \mathrm{L})$

PCO2 $(\mathrm{mmHg})$

AnGap (mmol/L)

$\mathrm{Na}(\mathrm{mmol} / \mathrm{L})$

$\mathrm{K}(\mathrm{mmol} / \mathrm{L})$

$\mathrm{Cl}(\mathrm{mmol} / \mathrm{L})$

$\mathrm{Ca}++(\mathrm{mmol} / \mathrm{L})$
$7.34-7.43$

22 - 29

$38-48$

$133-150$

$3-5.3$

$97-109$

$1.5-1.56$
7.34

7.43

29

58

12

135

4.2

98

Not measured
31.7

51

14

147

3

105

Procyte $^{\oplus}$ / Catalyst Dx ${ }^{\circledast}$ - Idexx Laboratories 
eye and the reaction was quickly obvious. The size of the palpebral fissure of the right eye increased significantly compared to the left eye. The tentative diagnosis of equine grass sikkness was substantiated. The horse was euthanized based on the poor prognosis and lack of response to treatment. A gross necropsy was performed. The colon was mildly impacted, but the other organs were grossly normal. The ileum was completely removed and a $4 \mathrm{~cm}$ long segment was fixed in $4 \%$ formalin and was sent to the Institute for Pathology of the University of Veterinary Medicine Hannover Foundation for further examination.

\section{Histopathology}

A cross section of the ileum was embedded routinely in paraffin wax. As a control, a paraffin-embedded ileal sample was used which had been collected during necropsy from a horse subjected to euthanasia for reasons other than gastrointestinal or neurological disease. In the HE stained ileal section of the affected horse a nearly complete depletion of neurons within the autonomic ganglia of the submucosal plexus was found (Fig. 2a). In three ganglia of the myenteric plexus of the examined section only one degenerating chromatolytic neuron each was present while the remaining ganglia were completely devoid of nerve cells. In the HE stained section of the ileum of the control horse varying numbers of normal appearing nerve cells were present (Fig. 4b).

\section{Discussion}

There are several studies on equine grass sickness, mainly from the United Kingdom (UK). Frustratingly, the pathogenesis of this disease has not been definitively identified and described until today. From Germany only few case reports exist. One case of chronic EGS was identified on a Northfriesian island (Schulze et al. 1997), and a case series of six cases of acute/subacute EGS from southern Germany and Switzerland has been published (Wehrli Eser et al. 2000). In all of these cases the horses were euthanized and the inciting cause of the disease could not be determined. A similar situation applies to single case reports from our neighboring countries Austria (Wlaschitz and Url 2004), Holland (Leendertse 1993) and France (Lhomme et al. 1996).

The studies from the United Kingdom have identified many risk factors. Our two-year old stallion matches the risk group of young horses from about 2 to 10 years (Wylie et al. 2014). He was on pasture together with other horses of the same age range which were not affected. The days before onset of disease were summer days with temperatures of over $22^{\circ} \mathrm{C}$. Nevertheless, there had also been some rainy days. Thus, the weather conditions did not match the weather-related risk factors described in studies such as dry weather, more sun hours, periods after cooler weather and frost days. A few days before the stallion showed clinical signs the herd had been transferred to a different pasture. Changing pasture within 14 days prior to the disease has been identified as a risk factor for EGS in some studies (Wood et al. 1998). The fact that cograzers of the same age are not necessarily affected is well known for EGS. Often only single horses are affected, especially in the reported cases in continental Europe (Schulze et al. 1997, Wehrli Eser et al. 2000). Reports of herd outbreaks are rare (Girling et al. 2017). The reason for this is unknown because usually several horses of one herd are exposed to the same risk factors.

Often discussed as a causative agent of EGS is Clostridium botulinum type $\mathrm{C}$. Clostridium botulinum is able to produce a neurotoxin inside the gastrointestinal tract of horses. There are two hypotheses about potential clostridial etiologies of EGS. First, it could be a matter of the amount of bacteria ingested together with grass or other feed. Second, the amount of bacteria or toxin might be less important but it could be a matter of the immune response of the individual horse. Both possibilities could be an explanation why co-grazing horses often are not affected by the disease. Current research in the UK focuses on the role of clostridium botulinum type $\mathrm{C}$ as the main cause of grass sickness. Previous studies have shown that the concentration of Clostridium botulinum type $C$ toxin is high in the intestine of acute cases. It is also known that horses with low levels of serum antibodies to the bacteria and its toxins are at increased risk for developing the disease. Recent epidemiological studies have also been able to show an increased risk when grass is contaminated by soil or birds present on the pasture. Obviously, it would have been interesting to determine the presence of Clostridium botulinum or the concentration of $C$. botulinum type $C$ neurotoxin within the intestine in this case as well, but fecal samples were not obtained in this case.

Disease progressed quickly in the present case. However, some of the symptoms were not typical for an acute course as described in the literature. The horse presented with massive gastrointestinal reflux, and this is one of the main signs of acute EGS. The resulting abdominal pain and the noted dysphagia were also quite typical. Bilateral ptosis as seen in our case is common in all stages of disease. But rhinitis sicca, penile prolapse and a "tucked-up" silhovette, which all developed within the few days of hospitalization, are normally only seen in subacute and chronic cases. Furthermore, he did not only suffer from weight loss due to anorexia, but he was in poor body condition already when he presented to the clinic. The body temperature was subnormal. In descriptions of EGS horses pyrexia is often mentioned, but subnormal temperature occurs in chronic cases. So this case demonstrates that clear classification of the course of disease based on clinical signs is not always possible. In this case disease was of acute onset but seemed more subacute in progression with some features of chronic disease. Laboratory abnormalities were interpreted as secondary to intestinal dysmotility and anorexia. The most conspicuous finding was the marked azotemia which likely resulted from fluid sequestration into the small intestine and subsequent hypovolemia and renal hypoperfusion, i.e. prerenal azotemia. After the horse had received initial fluid therapy, the creatinine was decreased to normal limits but urea was still increased, indicating improved renal perfusion. There is no specific curative treatment for acute and subacute cases. Usually, these horses have to be euthanized, otherwise they die due to cardiovascular failure or gastric rupture. Chronic cases can survive with intensive symptomatic treatment, survival is approximately $50 \%$.

In the present case the decision for euthanasia was made because of the horse's worsening clinical condition and poor 
prognosis. Nevertheless, for many horse owners it is important to have a diagnosis. So EGS should always be considered when symptoms like colic, reflux resulting, gastrointestinal hypomotility, ptosis and dysphagia occur together. Cases of colon impaction with an unusual course or lack of response to treatment can also be caused by EGS. Although ileal histopathology is the gold standard, collection of an ileal sample ante mortem is quite invasive. Therefore, the authors propose to make use of the phenylephrine test in clinical cases, as described above. It is a very simple, quick test suitable for equine ambulatory practice with an obvious result and it is suitable for showing and explaining the situation to the owner. This test can support the suspected diagnosis of EGS and help with decisionmaking. Owners should be supported in prevention of EGS on their premises. They may try to avoid the known risk factors, but unfortunately it is difficult to completely prevent EGS until the cause is better known. Our conclusion for equine practitioners should be to consider Grass Sickness in unclear cases of colic or weight loss even though it still only occurs sporadically in Germany and other continental European countries.

\section{References}

Bendixen H. (1946) Grass sickness in Denmark. Maanedsskr. Dyrlaeger 58, 41-62

Doxey D. L., Gilmour J. S., Milne E. M. (1991) A comparative study of normal equine populations and those with grass sickness (dysautonomia) in eastern Scotland. Equine Vet. J. 23, 365-369; DOI 10.1111/i.2042-3306.1991.tb03739.x

Girling S. J., Fraser M. A., Richardson D., Harley J., Ireland J. L., Naylor A., Milne E. (2017) An acute outbreak of equine dysautonomia (equine grass sickness) in a group of eight Przewalski s horses (Equus ferus [caballus] przewalskii). Equine Vet. Educ. 29, 358-361; DOI 10.1111/eve.12493

Hahn C. N., Mayhew I. G. (2000) Studies on the experimental induction of ptosis in horses. Vet. J. 160, 220-224; DOI 10.1053/tvil.2000.0493

Jago R. C., Scholes S., Mair T. S., Pearson G. R., Pirie R. S., Handel I., Milne E. M., Coyle F., McGorum B. C. (2017) Histological assessment of -amyloid precursor protein immunolabelled rectal biopsies aids diagnosis of equine grass sickness. Equine Vet. J. 50, 22-28; DOI 10.1111 evj.12710

Leendertse I. P. (1993) A horse with grass sickness. Tiidschr. Diergeneeskd. 118, 365-366
Lhomme C., CollobertLaugier C., Amardeilh M. F., Delverdier M. (1996) Equine dysautonomia: an anatomoclinical study of 8 cases. Rev. Med. Vet-Toulouse 147, 805-812

Lyle C. , Pirie R. S. (2009) Equine grass sickness. In Pract. 31, 2632; DOI 10.1136/inpract.31.1.26

McCarthy H. E., French N. P., Edwards G. B., Poxton I. R., Kelly D. F., Payne-Johnson C. E., Miller K., Proudman C. J. (2004) Equine grass sickness is associated with low antibody levels to Clostridium botulinum: a matched case-control study. Equine Vet. J. 36, 123 129; DOI 10.2746/042516404486861 1

Michl J., Modarai M., Edwards S., Heinrich M. (2011) Metabolomic analysis of Ranunculus spp. as potential agents involved in the etiology of equine grass sickness. J. Agr. Food Chem. 59, 1038810393; DOI 10.1021/jf201430k

Obel A. -L. (1955) Studies on grass sickness. The morphological picture with special reference to the vegetative nervous system. J. Comp. Pathol. 65, 334-346

Pirie R. S., Jago R. C., Hudson N. P. H. (2014) Equine grass sickness. Equine Vet J. 46, 545-553; DOI 10.1111/evj12254

Protopapas K.F., Spanoudes K. A. M., Diakakis N. E., Brellou G. D. (2012) Equine grass sickness in Cyprus: a case report. Turk. J. Vet. Anim. Sci. 36, 85-87; DOI 10.3906/vet-1102-764

Scholes S. F. E., Vaillant C., Peacock P., Edwards G. B., Kelly D. F. (1993a) Enteric neuropathy in horses with grass sickness. Vet. Rec. 132, 647-651; DOI 10.1136/vr.132.26.647

Scholes S. F. E., Vaillant C., Peacock P., Edwards G. B., Kelly D. F. (1993b) Diagnosis of grass sickness by ileal biopsy. Vet. Rec. 133, 7-10; DOI 10.1136/vr.133.1.7

Schulze C., Venner M., Pohlenz J. (1997) Chronische Graskrankheit (Equine Dysautonomie) bei einer zweieinhalb-jährigen IsländerStute auf einer nordfriesischen Insel. Pferdeheilkunde 13, 345350; DOI 10.21836/PEM19970405

Schwarz B., Brunthaler R., Hahn C., van den Hoven R. (2012) Outbreaks of equine grass sickness in Hungary. Vet. Rec. 170, 75-77; DOI 10.1136/vr. 100141

Wehrli Eser M., Feige K., Hilbe M. (2000) Klinische Symptomatik und Diagnostik bei Pferden mit akuter Grass sickness in der Schweiz und in Süddeutschland. Pferdeheilkunde 16, 138-143

Wlaschitz S., Url A. (2004) The first case of chronic grass sickness in Austria. Wien. Tierarztl. Mschr. 91, 42-45

Wood J. L. N., Milne E. M., Doxey D. L. (1998) A case-control study of grass sickness (equine dysautonomia) in the United Kingdom. Vet. J. 156, 7-14; DOI 10.1016/S1090-0233(98)80055-5

Wylie C. E., Shaw D. J., Fordyce F. M., Lilly A., McGorum B. C. (2014) Equine grass sickness in Scotland: a case-control study of signalement and meteorology-related risk factors. Equine Vet. J., 64-71; DOI 10.1111/evj.12077 